\title{
Pengaruh Tingkat Kekompakan Ruang (Urban Compactness) terhadap Tingkat Emisi Gas Rumah Kaca pada Sektor Energi Bidang Transportasi di Kota Malang
}

\author{
Indah Wahyuning Prihastuty dan Ketut Dewi Martha Erli Handayeni \\ Jurusan Perencanaan Wilayah dan Kota, FTSP, Institut Teknologi Sepuluh Nopember (ITS) \\ Jl. Arief Rahman Hakim, Surabaya 60111 Indonesia \\ e-mail: erli.martha@urplan.its.ac.id
}

\begin{abstract}
Abstrak- Kota Malang adalah kota dengan tingkat pertumbuhan penduduk tinggi, hal tersebut mengakibatkan adanya gejala urban sprawl yang berdampak pada pertambahan panjang perjalanan yang dibutuhkan. Peningkatan panjang perjalanan tersebut juga berdampak pada peningkatan jumlah kendaraan dan konsumsi energinya. Penelitian ini bertujuan untuk menganalisis adanya pengaruh bentuk kota (kekompakan ruang) terhadap emisi yang dihasilkan. Analisis dilakukan dalam 3 tahap, tahap pertama mengelompokkan tingkat kekompakan ruang kota malang, tahap kedua menghitung tingkat emisi pada tiap kelompok kekompakan ruang, tahap ketiga melakukan pemodelan regresi linier berganda untuk meneliti pengaruh kekompakan ruang terhadap tingkat emisi. Berdasarkan hasil penelitian, Kota Malang dibagi menjadi 3 kelompok kekompakan ruang yaitu tinggi, sedang dan rendah. Tingkat emisi pada kelompok kekompakan tinggi adalah $19,7 \mathrm{Kg} \mathrm{CO}_{2}$, kekompkan sedang adalah $25,9 \mathrm{Kg} \mathrm{CO} 2$ dan kekompakan rendah adalah 26 $\mathrm{Kg} \mathrm{CO}_{2}$. Perbedaan tingkat kekompakan ruang mempengaruhi perbedaan tingkat emisinya. Hasil permodelan dengan regresi linier berganda, diperoleh $Y=6.167 .233,715+42.771,992$ (kepadatan penduduk) - 59.629,983 (kepadatan lahan terbangun) - 9.039.849,863 (keragaman guna lahan). Dari hasil tersebut diketahui bahwa terdapat pengaruh yang signifikan antara kekompakan ruang dengan tingkat emisinya, dimana variabel yang paling berpengaruh adalah indeks keragaman guna lahan.
\end{abstract}

Kata Kunci- Emisi Bidang Energi Sektor Transportasi, Emisi Gas Rumah Kaca $\left(\mathrm{CO}_{2}\right)$, Kekompakan Ruang.

\section{PENDAHULUAN}

$\mathrm{K}$ OTA Malang merupakan salah satu kota yang berada di Provinsi Jawa Timur. Ju]mlah penduduk Kota Malang mencapai 840.803 pada tahun 2013 dan mengalami peningkatan sebesar $0.86 \%$ tiap tahunnya [1] dengan kepadatan penduduk sebesar 7.639 jiwa $/ \mathrm{km} 2$ dan merupakan kota dengan kepadatan tinggi nomor 17 di Indonesia [2]. Kota Malang sudah mengalami over population. Kota Malang memiliki bentuk perkembangan pita (ribbon pattern) pada jalur-jalur sirkulasi utama kota mendorong terjadinya urban sprawling [3].

Fenomena urban sprawl tersebut mengakibatkan berbagai dampak negatif, salah satunya adalah meningkatnya mobilitas penduduk [4]. Peningkatan mobilitas penduduk sub-urban tersebut terjadi karena kebutuhan penduduk untuk memenuhi kebutuhan sehari-hari di pusat kota [5]. Hal tersebut dapat dilihat dari jumlah kendaraan bermotor di Kota Malang juga mengalami peningkatan dari tahun 2012 sebanyak 471.272 unit menjadi 487.187 unit pada tahun 2013 [6]. Peningkatan jumlah kendaraan bermotor di Kota Malang tersebut akan memberi dampak pada penurunan Level of Service (LOS) terutama pada jalan-jalan utama memasuki pusat Kota Malang [5].

Peningkatan sarana trasnportasi akan berakibat pada peningkatan konsumsi energy [6]. Hal tersebut dapat dilihat dari emisi gas rumah kaca Kota Malang yakni sebanyak 1.224.225 ton $\mathrm{CO}_{2}$, dimana sektor konsumsi energi menyumbang sebanyak 1.008.229 ton $\mathrm{CO}_{2}$ pada tahun 2010 [7]. Estimasi emisi gas rumah kaca oleh sektor energi dan transportasi akan meningkat menjadi 1.880 .447 ton $\mathrm{CO}_{2}$ pada tahun 2020. Berdasar estimasi emisi tahun 2020, dapat dilihat bahwa emisi dalam 10 tahun, dapat meningkat sebanyak 872.218 ton $\mathrm{CO}_{2}$ atau setara dengan $86 \%$ dari total emisi tahun 2010 [8].

Selain disebabkan oleh peningkatan jumlah kendaraan dan konsumsi energi, emisi $\mathrm{CO}_{2}$ juga dapat dipengaruhi oleh bentuk suatu kota [9][10][11]. Hal tersebut juga diperkuat, bahwa semakin kompak bentuk suatu kota maka semakin efisien energi yang digunakan. Berdasarkan teori yang dikemukakan oleh berbagai ahli tersebut, penelitian ini bertujuan untuk mengkaji apakah bentuk ruang yang ditinjau dari tingkat kekompakan ruang (urban compactness) berpengaruh terhadap tingkat emisinya di Kota Malang.

\section{II.METODE PENELITIAN}

\section{A. Jenis dan Pendekatan Penelitian}

Pendekatan ini menggunakan pendekatan rasionalisme dalam penyusunan konseptualisasi teoritik untuk memberikan pemaknaan indikator identifikasi urban compactness dan identifikasi pengaruh urban compactness dalam pengurangan emisi [12]. Adapun jenis penelitian yang digunakan merupakan deskriptif-kuantitatif.

\section{B. Variabel Penelitian}

Variabel penelitian yang digunakan untuk mengukur tingkat kekompakan ruang Kota Malang adalah variabel kepadatan penduduk, kepadatan lahan terbangun, indeks keragaman guna lahan, ketersediaan fasilitas dan laju pertumbuhan penduduk. Sedangkan variabel yang digunakan untuk menghitung tingkat emisi pada masing-masing kelurahan di Kota Malang adalah data jumlah energi transportasi yang digunakan pada tiap rumah 
tangga dalam jangka waktu 1 (satu) minggu, dan juga variabel jenis bahan bakar yang digunakan.

\section{Metode Pengumpulan Data}

Pengumpulan data dilakukan melalui survey sekunder dan survey primer. Survey sekunder dilakukan untuk mendapat data-data kepadatan penduduk, kepadatan terbangun, ketersediaan fasilitas, keragaman penduduk dan laju pertumbuhan penduduk. Survey primer dilakukan untuk mendapat data jumlah konsumsi energi dan jenis bahan bakar.

Survey primer dilakukan pada sampel yang diperoleh dari 228.270 populasi rumah tangga di Kota Malang dengan tingkat kesalahan (error) sebesar 7\% sehhingga diperoleh sampel sebanyak 204 rumah tangga. Pengambilan sampel dilakukan dengan teknik proportional random sampling, dimana sampel diambil secara proporsional menurut kelurahan di Kota Malang dan dipilih secara acak/random.

\section{D.Metode Analisis}

\section{Mengelompokan Pola Kekompakan Ruang di Kota Malang}

Analisis identifikasi tingkat struktur dan pola kekompakan ruang Kota Malang terbentuk berdasarkan variabel-variabel kekompakan ruang dilakukan dengan teknik cluster hirarki dengan menggunakan software SPSS versi 11. Variabel kekompakan ruang tersebut adalah variabel kepadatan penduduk, kepadatan terbangun, ketersediaan fasilitas, keragaman guna lahan dan laju pertumbuhan penduduk.

Nilai dari keseluruhan variabel di input pada SPSS kemudian dianalisis menggunakan teknik cluster hirarki, kemudian pada outputnya akan dihasilkan beberapa cluster dengan tingkat kekompakan ruang yang berbeda. Hasil cluster kemudian dituang dalam bentuk peta menggunakan software ArcGIS versi 10.1. Hasil analisis akan terbentuk 3 cluster dengan tingkat kekompakan ruang yang berbeda. Hasil cluster yang didapat harus dilihat nilai signifikansinya, apabila nilai signifikansi pada tabel Anova kurang dari 0,05, maka hasil tersebut dinyatakan signifikan dan dapat digunakan. Penamaan tingkat kekompakan pada tiap cluster yakni dilihat dari kondisi eksisting serta perbandingan nilai pada tiap variabel kekompakan ruang.

2. Menghitung Tingkat Konsumsi Energi dan Tingkat Emisi Gas Rumah Kaca yang ditimbulkan oleh Sektor Transportasi Kota Malang

Untuk menghitung tingkat konsumsi energi dan emisi gas rumah kaca, dilakukan dengan menggunakan rumus perhitungan matematis tingkat emisi menurut [13] yakni :

\section{Emisi = Konsumsi bahan bakar (Liter/tahun) $\mathrm{x}$ Faktor emisi (Kg/Liter)}

Dimana faktor emisi adalah suatu nilai yang representatif dengan polutan yang dilepaskan.
Tabel 1.

Tabel faktor emisi

\begin{tabular}{cc}
\hline \hline Jenis bahan bakar & Faktor emisi \\
\hline Gasoline & $2,33 \mathrm{~kg} \mathrm{CO} 2 / \mathrm{Liter}$ \\
Diesel & $2,62 \mathrm{~kg} \mathrm{CO} 2 / \mathrm{Liter}$ \\
\hline \hline
\end{tabular}

Sebelum melakukan perhitungan tersebut data data yang dibutuhkan didapat dari hasil wawancara kepada penduduk Kota Malang. Data yang di input dalam proses hitungan emisi adalah data rata-rata konsumsi energi tiap kelurahan dalam satuan waktu minggu berdasarkan sampel. Setelah mendapatkan data untuk menghitung tingkat emisi, kemudian analisis dilakukan menggunakan persamaan matematis mengenai perhitungan tingkat emisi seperti persamaan diatas. Perhitungan rata-rata total emisi dilakukan berdasar cluster kekompakan, guna mengetahui dan membuktikan teori kekompakan ruang, dimana semakin kompak sebuah ruang maka semakin kecil emisi yang dihasilkan, dan begitu pula sebaliknya

3. Menganalisis Pengaruh Urban Compactness terhadap Emisi Gas Rumah Kaca di Kota Malang

Pada tahap analisis ini, data variabel $\mathrm{Y}$ yang digunakan adalah data tingkat emisi berdasar total jumlah rumah tangga pada tiap kelurahan. Data variabel Y pada tahap analisis ini menggunakan satuan waktu tahun karena data variabel $\mathrm{X}$ (variabel-variabel kekompakan ruang) yang di input adalah data basis kelurahan dengan satuan waktu tahun. Setelah diperoleh hasil tingkat emisi gas rumah kaca yang dihasilkan (Y) serta nilai-nilai variabel kekompakan ruang (X), data tersebut kemudian dianalisis menggunakan teknik regresi linier berganda dengan tingkat emisi gas rumah kaca sebagai variabel terikat dan 5 variabel kekompakan ruang sebagai variabel bebasnya.

Tujuan dari metode regresi linier berganda ini bertujuan untuk mengukur pengaruh antara lebih dari satu variabel prediktor (variabel bebas) terhadap variabel terikat. Sebelum menjadi sebuah persamaan linier, data diolah menggunakan software SPSS agar mendapat konstanta dari tiap variabel bebas. Untuk mendapatkan model yang valid, dapat dilakukan uji asumsi klasik yang perlu dilakukan adalah uji multikolinieritas, autokorelasi, heteroskedastisitas dan normalitas.

\section{HASIL DAN PEMBAHASAN}

\section{A. Mengelompokan Pola Kekompakan Ruang di Kota Malang}

Berdasarkan hasil analisis cluster hirarki pada 5 variabel kekompakan ruang, didapatkan hasil bahwa Kota Malang terbagi menjadi 3 kelompok dengan tingkat kekompakan ruang rendah, sedang dan tinggi. Cluster kekompakan ruang tinggi memiliki 34 kelurahan, kekompakan ruang sedang 7 kelurahan dan kekompakan ruang rendah 13 kelurahan. Cluster kekompakan tinggi berada di pusat Kota Malang, karena kepadatan terangun dan keragaman guna lahan pada pusat kota tergolong lebih tinggi jika dibandingkan dengan cluster lain. 
Cluster kekompakan sedang, berperan sebagai jembatan antara cluster rendah dan cluster tinggi. Cluster kekompakan ruang rendah, berada di ujung-ujung Kota Malang dengan persentase lahan pertanian dan lahan kering yang lebih tinggi dibandingkan dengan lahan terbangunnya.
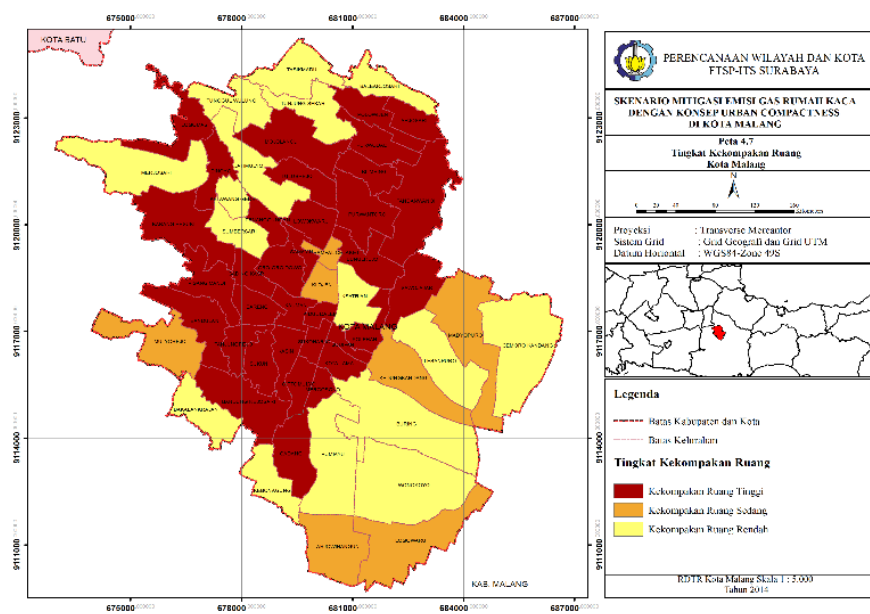

Gambar 1. Tingkat kekompakan ruang di kota malang.

B. Menghitung Tingkat Konsumsi Energi dan Tingkat Emisi Gas Rumah Kaca yang Ditimbulkan oleh Sektor Transportasi Kota Malang

Dalam analisis ini, data yang digunakan adalah data dari hasil survey kuisioner pada sampel rumah tangga di Kota Malang. Dari hasil survey,pada cluster kekompakan ruang tinggi didapatkan data bahwa rata-rata konsusmsi energi transportasi per rumah tangga adalah 8,4 liter/minggu, pada cluster kekompakan ruang sedang adalah 11,1 liter/minggu, dan pada cluster kekompakan ruang rendah adalah 11,1 liter/minggu.

Berdasarkan tingkat konsumsi energi transportasi tersebut, diperoleh tingkat emisi pada masing-masing cluster kekompakan ruang. Pada cluster kekompakan tinggi tingkat emisi yang dihasilkan adalah $19,7 \mathrm{~kg} \mathrm{CO}_{2} / \mathrm{minggu}$, pada cluster kekompakan ruang sedang sebesar 25,9 $\mathrm{kg} \mathrm{CO} /$ minggu dan pada cluster kekompakan sebesar $26 \mathrm{~kg} \mathrm{CO}_{2} /$ minggu. Dari hasil tersebut, diperoleh kesimpulan bahwa semakin tinggi tingkat kekompakan ruang, maka tingkat emisi yang dihasilkan semakin kecil dan begitu pula sebaliknya.

\section{Menganalisis Pengaruh Urban Compactness terhadap Emisi Gas Rumah Kaca di Kota Malang}

Pada analisis ini, data emisi yang digunakan adalah data total emisi seluruhnya tiap kelurahan di Kota Malang. Hasil analisis pada output SPSS menyatakan bahwa nilai signifikansi model $<0,05$ (tingkat kesalahan 5\%) sehingga model dapat dikatakan signifikan.

Tabel 2.

Tabel Anova (nilai signifikansi).

\begin{tabular}{ccrccc}
\hline \hline Model & $\begin{array}{c}\text { Sum of } \\
\text { Squares }\end{array}$ & df & $\begin{array}{c}\text { Mean } \\
\text { Square }\end{array}$ & F & Sig \\
\hline Regresion & $8,791 \mathrm{E} 14$ & 5 & $1,758 \mathrm{E} 14$ & 8,500 &, $000^{\mathrm{a}}$ \\
Residual & $1,055 \mathrm{E} 15$ & 51 & $2,069 \mathrm{E} 13$ & & \\
Total & $1,934 \mathrm{E} 15$ & 56 & & & \\
\hline \hline
\end{tabular}

Pada tabel koefisien, terlihat bahwa nilai signifikansi beberapa variabel memiliki nilai melebihi nilai $0,05(5 \%)$ sehingga model harus dianalisis ulang dengan reduksi variabel secara bertahap, dimulai dari variabel yang memiliki nilai signifikansi paling besar.

Tabel 2.

Tabel koefisien (nilai koefisien dan nilai signifikansi) sebelum reduksi variabel.

\begin{tabular}{|c|c|c|c|}
\hline \multirow[t]{2}{*}{ Model } & $\begin{array}{l}\text { Unstandardized } \\
\text { Coefficients }\end{array}$ & $\mathrm{t}$ & Sig \\
\hline & $\mathrm{B}$ & & \\
\hline (Constant) & 2094208,763 & ,778 & ,440 \\
\hline $\begin{array}{l}\text { Kepadatan } \\
\text { penduduk }\end{array}$ & 45872,913 & 5,995 &, 000 \\
\hline $\begin{array}{l}\text { Kepadatan } \\
\text { terbangun }\end{array}$ & $-40354,786$ & $-1,367$ & , 178 \\
\hline $\begin{array}{l}\text { Ketersediaan } \\
\text { fasilitas }\end{array}$ & 18563,754 & 2,136 & ,037 \\
\hline $\begin{array}{c}\text { Keragaman } \\
\text { guna lahan } \\
\text { Laju }\end{array}$ & $-8838080,084$ & $-2,456$ & ,018 \\
\hline $\begin{array}{c}\text { pertumbuhan } \\
\text { penduduk }\end{array}$ & 286010,715 & 1,324 & ,191 \\
\hline
\end{tabular}

Hasil akhir yang diperoleh dari analisis regresi linier berganda yakni bahwa variabel yang mempengaruhi tingkat emisi secara signifikan adalah kepadatan penduduk, kepadatan lahan terbangun dan keragaman guna lahan.

Tabel 3.

Tabel koefisien (nilai koefisien dan nilai signifikansi) setelah reduksi variabel.

\begin{tabular}{cccc}
\hline \hline Model & $\begin{array}{c}\text { Unstandardized } \\
\text { Coefficients } \\
\text { B }\end{array}$ & t & Sig \\
\hline $\begin{array}{c}\text { Constant) } \\
\text { Kepadatan } \\
\text { penduduk }\end{array}$ & 6167233,715 & 3,280 &, 002 \\
$\begin{array}{c}\text { Kepadatan } \\
\text { terbangun }\end{array}$ & 42771,922 & 5,546 &, 000 \\
$\begin{array}{c}\text { Keragaman } \\
\text { guna lahan }\end{array}$ & $-59629,983$ & $-2,140$ &, 037 \\
\hline
\end{tabular}

Berdasar hasil analisis regresi liner berganda antara variabelvariabel kekompakan ruang dengan variabel total emisi, didapat hasil persamaan regresi yakni $\mathbf{Y}=\mathbf{6 . 1 6 7 . 2 3 3 , 7 1 5}+$

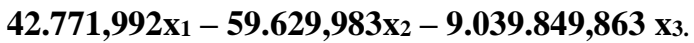

Pada model regresi, tersebut dilakukan uji multokolinearitas dilihat dari nilai VIF keseluruhan variabel kurang dari nilai 5 (lima), sehingga tidak terjadi multikolinieritas pada model regresi. Kemudian dilakukan uji autokorelasi dengan melihat nilai durbin watson $(1,833)$ yang mendekati angka 2 , maka model regresi bebas autokorelasi. Pada uji heteroskedastisitas dilihat plot yang tersebar tidak memiliki pola tertentu, sehingga model regresi bebas dari heteroskedastisitas. Scatter Plot pada uji normalitas terdistribusi mengikuti garis diagonal, sehingga model regresi terdistribusi normal.

Berdasarkan uji-uji tersebut, model regresi linier berganda yang dipoleh, dapat digunakan. Pada persamaan tersebut, 
variabel $\mathrm{Y}$ adalah variabel total emisi, variabel $\mathrm{X} 1$ adalah variabel kepadatan penduduk, X2 adalah variabel kepadatan lahan terbangun dan X3 adalah variabel indeks keragaman guna lahan. Pada persamaan tersebut dapat dilihat pula bahwa variabel yang paling mempengaruhi emisi di Kota Malang adalah variabel indeks keragaman guna lahan (dilihat dari nilai koefisien terbesar).

Persamaan regresi linier berganda yang dihasilkan, menunjukkan bahwa:

a) konstanta sebesar 6.167.233,715 menyatakan bahwa jika tidak ada penambahan atau penurunan terhadap variabel $\mathrm{x} 1$ hingga $\mathrm{x} 2$, maka tingkat emisi akan sebesar 6.167.233,715 Kg CO2.

b) Koefisien regresi x1 (kepadatan penduduk) sebesar 42.771,992 menyatakan bahwa setiap penambahan kepadatan penduduk sebesar 1 satuan (1 Jiwa/Ha) akan berpengaruh pada peningkatan tingkat emisi sebesar 42.771,992 Kg CO2 dengan asumsi variabel lainnya tetap. Sehingga, dapat disimpulkan bahwa semakin besar kepadatan penduduk maka tingkat emisi akan semakin banyak.

c) Koefisien regresi $x_{2}$ (kepadatan lahan terbangun) sebesar - 59.629,983 menyatakan bahwa setiap penambahan kepadatan lahan terbangun sebesar 1 satuan (1\%) akan berpengaruh pada penurunan tingkat emisi sebesar 59.629,983 $\mathrm{Kg} \mathrm{CO}_{2}$ dengan asumsi variabel lainnya tetap. Sehingga, dapat disimpulkan bahwa semakin padat lahan terbangun, maka tingkat emisi akan menurun.

d) Koefisien regresi $\mathrm{x}_{3}$ (keragaman guna lahan) sebesar 9.039.849,863 menyatakan bahwa setiap penambahan keragaman guna lahan sebesar 1 satuan (1 indeks) akan berpengaruh pada penurunan tingkat emisi sebesar 9.039.849,863 $\mathrm{Kg} \mathrm{CO} 2$ dengan asumsi variabel lainnya tetap. Sehingga, dapat disimpulkan bahwa semakin besar indeks keragaman guna lahan, maka tingkat emisi juga akan semakin kecil.

\section{KESIMPULAN}

Berdasarkan hasil analisis yang telah dilakukan pada pembahasan sebelumnya, maka dapat diperoleh kesimpulan dari penelitian ini sebagai berikut:

1. Berdasarkan hasil analisis cluster hirarki di Kota Malang, didapatkan 3 kelompok cluster kekompakan ruang, yakni kekompakan ruang tinggi, kekompakan ruang rendah dan kekompakan ruang sedang. Terdapat 34 kelurahan yang termasuk kategori cluster kekompakan tinggi, 7 kelurahan termasuk kategori kekompakan sedang dan 16 kelurahan termasuk kategori kekompakan ruang rendah.

2. Hasil perhitungan tingkat emisi menggunakan rumus emisi rata-rata tingkat emisi pada cluster 1 atau kekompakan ruang relatif tinggi sebesar 19,7 $\mathbf{~ k g ~ C O 2 / m i n g g u , ~ c l u s t e r ~}$ kekompakan ruang sedang sebesar 25,9 kg CO2/minggu, cluster kekompakan ruang rendah sebesar $26 \mathbf{~ k g}$ CO2/minggu. Semakin tinggi tingkat kekompakan ruangnya, maka semakin rendah tingkat emisinya dan begitu pula sebaliknya.

3. Hasil analisis regresi linier berganda menunjukan ada pengaruh/hubungan yang signifikan antara tingkat kekompakan ruang dengan tingkat emisinya. Model regresi linier berganda yang telah memenuhi uji asumsi klasik, diperoleh total emisi $=\mathbf{6 . 1 6 7 . 2 3 3 , 7 1 5}+\mathbf{4 2 . 7 7 1 , 9 9 2}$ kepadatan penduduk - 59.629,983 kepadatan lahan terbangun - 9.039.849,863 keragaman guna lahan, dimana variabel yang paling mempengaruhi total emisi gas rumah kaca pada sektor transportasi adalah variabel keragaman guna lahan.

\section{UCAPAN TERIMA KASIH}

Penulis I.W.P mengucapkan terima kasih kepada Ketut Dewi Martha Erli, S.T., M.T selaku dosen pembimbing, yang selalu memberi bimbingan selama penelitian. Kepada pihak pihak terkait yang turut membantu dalam penelitian.

\section{DAFTAR PUSTAKA}

[1] BPS. (2015). Kota Malang dalam Angka. Malang: Badan Pusat Statistik.

[2] wikipedia.com, Diakses pada Desember 2015.

[3] Wikantiyoso, H. (2013). Membangun Partisipasi Masyarakat Demi Menata Kota. Koran Malang Pos. Malang.

[4] Rachmadita, S.O. (2009). Arahan Kebijakan Modal Shift Kendaraan Pribadi ke Bus Kota untuk Pekerja Ulang-Alik Sidoarjo-Surabaya di Kecamatan Waru. Surabaya.

[5] Ambarwati. (2009). Travel Pattern Alteration in City of Developing Country due to Sustainable Transportation. Proceedings of the Eastern Asia Society for Transportation Studies, Vol.7.

[6] Kantor bersama samsat Kota Malang. (2013). Banyaknya Kendaraan Bermotor Berdasarkan Pada jenis Kendaraan.

[7] Axisa et al. (2012). Migration, urban growth and commuting distance in Toronto's commuter shed. Area Vol. 44 No. 3, pp. 344-355.

[8] http://www.paklim.org/index.php/id/about/climate-change-strategies-incities/strategy-in-malang.html. Diakses pada Desember 2015.

[9] Neuman. (2005). The Compact City Fallacy. Journal of Planning Education and Research, 11-26.

[10] Erling Holden, I. T. (2005). Three Challenges for the Compact City as a Sustainable Urban Form: Household Consumption of Energy and Transport in Eight Residential Areas in the Greater Oslo Region. Urban Studies Vol. 42, 2145-2166.

[11] Mike Jenks, E. B. (1996). The Compact City : A Sustainable Form? United Kingdom: Spon Press.

[12] Noeng Muhadjir, Metodologi Penelitian Kualitatif Edisi IV, (Yogyakarta: Rake Sarasin, 2002), h.148.

[13] IPCC. (2006). Guidelines for National Greenhouse Gas Inventories : vol 2. 